8. Hallak A, Jamjoom H,Hosseinzadeh T. Supernumerary nostrils: A case report and review. Aesthetic Plast Surg 2001; 25:241-3.

9. Nakamura $K$, Onizuka T. A case of supernumerary nostril. Plast Reconstr Surg 1987;80:436-41.

10. G. CUERVO DE LA CALLE, E. VIVIENTE RODRÍGUEZ, A. CAPITÁN GUARNIZO,etal, Supernumery nostril, Acta otorrinolaringol Esp 2004, 55:93-96
Address for Correspondence:

Prof. Dr. N.Radhakrishna, Government ENT.Hospital,

Koti, Hyderabad

Andhra Pradesh.

\title{
A CASE STUDY OF PLUMMER-VINSON SYNDROME
}

\author{
Vikas Sinha, ${ }^{*}$ Bela Prajapati, ${ }^{* *}$ Ajay George, ** Devang Gupta.**
}

\begin{abstract}
The case series presents the pattem of association of different co-morbid conditions of Plummer Vinson's Syndrome. The commonest morbidity is web at post cricoid level. The symptoms of dysphagia are more common and there appears to be a female preponderance. The presenting age us usually Sth decade. Although association with post cricoid carcinoma has beet reported but only 10\% of cases in the present series had carcinoma at the time of presentation. The effect of iron and B-complex supplementation has been clinically appraised and good symptomatic relief has been seen. Maybe this measure can prevent the progression to malignancy. Bouginage was effective in relieving symptoms in all the cases it was tried
\end{abstract}

Keywords : Plummer Vinson Syndrome, Postcricoid web.

\section{INTRODUCTION}

Plummer-Vinson syndrome or Patterson-Kelly syndrome is characterized by dysphagia which is usually due to upper esophageal web, anemia, splenomegaly and other features like angular chelitis and glossitis. A prospective study was conducted in $\mathrm{BJ}$ medical college, Ahmedabad with an aim to find out the age and sex incidence of this syndrome. To evaluate the results of iron and B-complex supplementation with esophageal dilation and find out relationship with post-cricoid carcinoma, if any.

\section{MATERIALS AND METHODS}

25 confirmed cases of Plummer-Vinson syndrome were included in the study after taking detail history and detail examination, all cases were investigated for all routine blood parameters including blood indices and radiological investigation barium swallow and other indicated investigations. The patients are subsequently put on iron and B-complex therapy. Rigid endoscopy was done, webs and strictures were dilated and biopsy of suspicious lesions was taken. The patients were adequately followed up and any needed further management was instituted.

\section{OBERVATIONS}

Out of 25 cases of the present series, 22 patients i.e. $88 \%$ were females and the rest were males. The age distribution is as shown in table A. 12 patients were in the $5^{\text {th }}$ decade of life. Next highest was 7 cases in $4^{\text {th }}$ decade of life. The remaining cases were sparsely distributed over the other decades. The youngest was 20 year old and the oldest was 65 -year old. 2 patients had a past history of oesophagoscopy and dilatation, where as 2 patients had a history of surgery for acid peptic disease. The symptomatology is as shown in Table B. All cases had dysphagia other symptoms like soreness of mouth, easy fatigability, palpitation, parasthesia, giddiness, dysponea and malena were present in varying proportions.

Grade I dysphagia where in patient has only difficulty in swallowing solids was present in $52 \%$ cases. Grade II dysphagia where in patient can take only semisolids was present in $36 \%$ patients. Grade III dysphagia where in patient can take only liquids was present in $8 \%$ cases. Difficulty to swallow even saliva i.e. grade IV was present in $4 \%$ cases. Among clinical features signs of iron deficiency, anemia like bald tongue, pallor, koilonychia were present in all cases. Angular chelitis and glossitis was present in $80 \%$ and $60 \%$ cases respectively. Splenomegaly was found only in 4 cases.

All patients had hemoglobin less than $10 \mathrm{gm} \%$ and 8 cases were severely anemic with hemoglobin less than $5 \mathrm{gm} \%$. Blood indices like PCV, MCV, MCHC, serum iron and total iron binding capacity revealed microcytic hypochromic anemia with iron deficiency in all cases. Urine analysis was normal in all cases. Stool examination revealed occult blood in 2 cases. Gastric analysis reveled achlorohydria in 3 cases. Radiological investigation reveled post cricoid web in 4 cases, benign stricture in 1 case, malignant stricture in 2 cases \& surprising normal finding in 12cases. All cases in spite of barium swallow findings underwent rigid oesophagoscopy under general anesthesia which showed post cricoid web in 15 cases. These webs were commonly situated on lateral wall. Stricture was present in 4 cases. Exophytic growth was seen in 2 cases which proved to be malignancy on biopsyand histo-pathological examination during endoscopy full dilation with gum elastic bougies was carried out in 19 cases. All patients except those with malignant growth were started on full diet next day itself iron and vitamin supplements was instituted in all cases.

*Professor and Head, **Assistant Professors, Department of Otolaryngology and Head and Neck Surgery, B.J.Medical College, (Civil Hospital), Ahmedabad, (Gujarat) 
Follow up was possible in 15 cases, duration of follow up ranged from 6 months to 2 years.

\section{DISCUSSION}

The incidence of PV syndrome in males in this study in a bit higher at $12 \%$ as against $4 \%$ reported in studies of $\mathrm{McNab}$ and Jones et al. This may be because of smaller size of sample. The higher incidence of PV syndrome in females can be attributed to inadequate dietary intake, chronic blood loss in form of menstruation and multi-parity. The age incidence also correlates to that observed in the above mentioned studies, though Jacob et al reported 2 cases below 20 years of age in their study of 52 cases, we didn't find any case less than 20 years. such an early presentation of this syndrome in extremely rare. The incidence of different clinical features like dysphagia, glossitis, koilonychia, splenomegaly etc. is same in this study as that reported in others studies. But splenomegaly in the region of $20 \%$ to $30 \%$ reported in the studies of Moersch \& Corner and McNab \& Jones does not correspond to the unexplained low incidence of $12 \%$ in our series.

The low incidence of abnormal barium swallow in our study also does not correspond to the high rates up to $90 \%$ in the series of Jacobs. This may be because webs which are the commonest abnormality can be easily over looked and can hardly be recognized on fluoroscopy unless there is considerable obstruction or retention of barium between double membranes. For better visualization of webs it is suggested that a thick paste should be used and rapid exposure after swallowing is essential. Also multiple antero-posterior and lateral views should be taken. Esophagoscopy is extremely important in the evaluation of patients of PV syndrome $80 \%$ of our cases had an abnormality. The post cricoid web being the commonest.

These webs are usually semi lunar or annular, are very thin and are covered with pink mucosa. They can be very easily ruptured by scope or bougies. A review of literature shows that $10 \%$ to $30 \%$ cases of PV syndrome go on to become malignancy of upper alimentary tract. In Lederman's series of 106 cases of post criocoid carcinoma 57\% had PV syndrome. In our series 2 cases turned out to be cases of post cricoid carcinoma. Paterson stated that post cricoid carcinoma was a not uncommon late sequel of the condition. Kelly at the same section of laryngology of the royal society of medicine in London at which Patterson described his cases, reported on dysphagia due to spasm at the level of postcricoid that he considered to be caused by severe neurosis. It has been reported in contemporary literature that iron and vitamin deficiency induced mucosal changes over a period of time become dysplastic and subsequently malignant. Theses changes can be reversed if adequate supplementation is instituted at early stages of disease.

\section{CONCLUSION}

PV syndrome has the highest incidence in females and in the fifth decade of life. Grade I dysphagia with soreness of mouth is the commonest presenting complaint. Major clinical signs of iron deficiency anemia like pale bald tongue, angular chelitis, pallor etc. are found in almost all cases. However, splenomegaly is not so common. The hematological picture is one of microcytic hypochromic anemia with iron deficiency: Web in the post-cricoid region is the commonest abnormality on barium swallow. However, its not possible to demonstrate this in all cases. There is definite relation between PV syndrome and post-cricoid carcinoma, biopsy of any suspicious lesion on endoscopy and regular follow up of all cases is essential.

Table A

\begin{tabular}{l|l|l}
\hline AGE (in yrs) & No. of Patients & \% \\
\hline 20 & 1 & 4 \\
$21-30$ & 3 & 12 \\
$31-40$ & 7 & 28 \\
$41-50$ & 12 & 48 \\
$51-60$ & 1 & 4 \\
$>60$ & 1 & 4 \\
Total & $\mathbf{2 5}$ & $\mathbf{1 0 0}$ \\
\hline
\end{tabular}

Table B

\begin{tabular}{l|l|l}
\hline Symptoms & No. of Patients & $\%$ \\
\hline Dysphagia & 25 & 100 \\
Soreness of mouth & 17 & 68 \\
Weakness & 21 & 84 \\
Palpitation & 10 & 40 \\
Parasthesiae & 10 & 40 \\
Dyspnoea & 6 & 24 \\
Giddiness & 3 & 12 \\
\hline
\end{tabular}

\section{REFERENCES}

1. Okamura H, Tsutsumi S, Inakai S, Eosophageal web in Plummer - Vinson syndrome. Laryngoscope 1988; 98 (9) : 994- 8

2. Waldenstrom $J$, Kjellberg $D R$, The roentgenological diagnosis of sideropenic dysphagia. Acta radiological, Stockholm1939; 20:618

3. Hoower WB, The syndrome of anemia, glossitis and dysphagia. New Engl J Med 1935 ; 213 (9) : 394-8

4. Paterson DR, A clinical type of dysphagia. The Journal of Laryngology, Rhinology and Otology, London 1919; $34: 289-291$.

5. Kelly $A B$, Spasm at the entrance of the oesophagus. The Journal of Lyryngology, Rhinology and Otology, London 1919; 34 : 285 - 289

6. Vinson PP, A case of cardiospasm with dilation and angulation of oesophagus. Medical Clinics of North America, Philadelphia. PA, 1919;3: 623-627

7. Plummer HS, Diffuse dilation of the oesophagus without anatomical stenosis (cardiospasm) A report of 91 cases, Journal of the American Medical Assosiation, Chicago, 1912; $58: 2013$ - 2015

\section{Address for correspondence \\ Dr. Vikas Sinha \\ Professor \& Head ENT drsinhavikas@yahoo.co.in}

B.J.Medical College, Ahmedabad - 380016 